Article

\title{
Visualization of Germination Proteins in Putative Bacillus cereus Germinosomes
}

\author{
Yan Wang ${ }^{1}$, Richard de Boer ${ }^{1}\left(\mathbb{D}\right.$, Norbert Vischer ${ }^{1}$, Pauline van Haastrecht ${ }^{1}$, Peter Setlow ${ }^{2}$ and \\ Stanley Brul ${ }^{1, *(\mathbb{C})}$ \\ 1 Molecular Biology and Microbial Food Safety, Swammerdam Institute for Life Sciences, University of \\ Amsterdam, Amsterdam, Science Park 904, 1098 XH, The Netherlands; y.wang5@uva.nl (Y.W.); \\ R.deBoer@uva.nl (R.d.B.); norbertvischer@gmail.com (N.V.); PaulinevanHaastrecht@outlook.com (P.v.H.) \\ 2 Department of Molecular Biology and Biophysics, UConn Health, Farmington, CT 06030-3305, USA; \\ setlow@uchc.edu \\ * Correspondence: S.Brul@uva.nl
}

Received: 21 June 2020; Accepted: 20 July 2020; Published: 22 July 2020

check for updates

\begin{abstract}
Bacillus cereus can survive in the form of spores for prolonged periods posing a serious problem for the manufacture of safe shelf-stable foods of optimal quality. Our study aims at increasing knowledge of $B$. cereus spores focusing primarily on germination mechanisms to develop novel milder food preservation strategies. Major features of $B$. cereus spores are a core with the genetic material encased by multiple protective layers, an important one being the spores' inner membrane (IM), the location of many important germination proteins. To study mechanisms involved in germination of $B$. cereus spores, we have examined the organization of germinant receptors (GRs) in spores' IM. Previous studies have indicated that in spores of B. cereus ATCC 14579 the L-alanine responsive GR, GerR, plays a major role in the germination process. In our study, the location of the GerR GR subunit, GerRB, in spores was examined as a C-terminal SGFP2 fusion protein expressed under the control of the gerR operon's promoter. Our results showed that: (i) the fluorescence maxima and integrated intensity in spores with plasmid-borne expression of GerRB-SGFP2 were significantly higher than in wild-type spores; (ii) western blot analysis confirmed the expression of the GerRB-SGFP2 fusion protein in spores; and (iii) fluorescence microscopy visualized GerRB-SGFP2 specific bright foci in $\sim 30 \%$ of individual dormant spores if only GerRB-SGFP2 was expressed, but, noticeably, in $\sim 85 \%$ of spores upon co-expression with GerRA and GerRC. Our data corroborates the notion that co-expression of GR subunits improves their stability. Finally, all spores displayed bright fluorescent foci upon expression of GerD-mScarlet-I under the control of the gerD promoter. We termed all fluorescent foci observed germinosomes, the term used for the IM foci of GRs in Bacillus subtilis spores. Our data are the first evidence for the existence of germinosomes in B. cereus spores.
\end{abstract}

Keywords: Bacillus cereus; spore; germinant receptor; germination protein; spore inner membrane

\section{Introduction}

In general, bacterial endospore formers comprise aerobically growing Bacillales species and anaerobic Clostridiales species. Bacillales species are ubiquitous in nature and can be found in soil, plants, insects and mammals. As such, they can easily contaminate food products and are often causative agents of foodborne disease [1]. For example, Bacillus cereus can lead to an emetic or diarrheal syndrome as a result of human consumption of contaminated foods in which outgrowing spores and their resulting vegetative cells have formed toxins [2]. Spores can survive for years or even decades in harsh conditions, including wet or dry heat, high pressure and radiation dense areas, due to spores' novel structure and many protective components and their metabolic dormancy [3,4]. 
In B. subtilis, a generally used model spore-former, the initiation of sporulation is largely dependent upon transcription factor Spo0A [5]. After this initiation, sporulating cells divide into a larger mother cell and a smaller forespore, and then the mother cell engulfs the forespore [6-8]. After engulfment, the forespore matures and ultimately is released from the mother cell as a highly resistant free spore in which metabolic activity has been silenced. The structure of a mature B. cereus spore is characterized by an outermost exosporium, then the outer and inner coat layers, an outer membrane, the large cortex peptidoglycan layer, then a layer of germ cell wall peptidoglycan and finally the inner membrane (IM). The IM contains typical plasma membrane phospholipids as well as a number of proteins, some of which are involved in spore germination, and lipid mobility in the dormant spores' IM is extremely low [9]. The core contains the DNA, essential macromolecules for survival and protective calcium dipicolinic acid (CaDPA).

Studies in B. subtilis identified the proteins that are most likely to interact somehow with physiological spore germinants, and these proteins have been termed germinant receptors (GRs). There are three major B. subtilis GRs-GerA, GerB and GerK-, and all are present in the IM and are made-up of A, B and C subunits [10,11]. Generally, subunit A is comprised of five or six predicted transmembrane (TM) domains and hydrophilic domains at the $\mathrm{N}$-and $\mathrm{C}$-termini, but the B subunit is comprised of only 10-12 TM domains. The A and B GR subunits are the ones most likely to be involved in recognition of amino acid germinants [12]. The GR C-subunit includes a predicted pre-lipoprotein signal sequence, suggesting that the $C$ subunit is anchored to the outer surface of the membrane via an N-terminally attached lipid moiety [13]. Spores are triggered to germinate in response to specific amino acids, sugars and purines. Upon GR triggering by a germinant the germination process proceeds beyond a point of no return (commitment) and leads to the release of CaDPA, hydrolysis of cortex peptidoglycan by cortex-lytic enzymes, the swelling of the core and finally full core hydration [10]. After this change, germinated spores enter into outgrowth that leads to the first vegetative cell division.

Bacillus cereus is a member of the Gram-positive, motile, rod-shaped endospore forming Bacillus cereus group; other well-known members of the B. cereus group are B. thuringiensis [14], B. anthracis [15], B. mycoides [16], B. weihenstephanensis [17], B. pseudomycoides [18], B. toyonensis [19] and B. cytotoxicus [20]. In B. subtilis spores, three types of proteins related to germination are located in the IM: GRs, GerD acting as a scaffold protein is almost certainly a lipoprotein [21] and SpoVA channel proteins for CaDPA. There are three GRs: GerA responding to L-alanine, and GerB and GerK that collaborate in responding to L-asparagine, D-glucose, D-fructose and potassium chloride [10]. In contrast, there are seven functional GRs-GerR, GerK, GerG, GerL, GerQ, GerI and GerS-in B. cereus ATCC 14579 spores [22]. In particular, GerR, with the order GerRA-GerRC-GerRB, has a critical role in spore germination in response to L-alanine, or inosine alone and in food products, for example meat broth and rice water [23].

In B. subtilis spores, GRs are localized in 1-3 IM foci, termed a germinosome, for which GerD acts as a scaffold for GR assembly [21,24]. Recent work by our laboratory, using super-resolution three-dimensional structured illumination microscopy (3D-SIM) as well as annular Rescan Confocal Microscopy has allowed us to quantify germinosomes in single spores as well as to monitor germinosome dynamics upon germinant addition to wild-type $B$. subtilis spores $[25,26]$.

In contrast to identification of germinosomes in B. subtilis spores, nothing is known about the location of germination proteins in $B$. cereus spores. Hence, here we aimed to use phase-contrast microscopy and the Nikon Eclipse Ti fluorescence microscope to see if we could visualize putative germinosomes in B. cereus spores, initially using a strongly enhanced green fluorescent protein (SGFP2) fused to the GerRB germination protein, and under the control of the native promoter of the gerR operon on a low-copy number plasmid to enhance chances of observing the fusion protein in wild-type spores. The results with this fusion were compared to those with spores of a B. cereus strain in which the plasmid contained the gerRB-SGFP2 fusion gene without the gerR promoter. Initial results with this first GerRB-SGFP2 fusion were promising, as $\sim 30 \%$ of spores carried likely germinosomes, but this result suggested using a plasmid carrying the entire gerR operon with gerRB fused to SGFP2 and under 
PgerR control. This plasmid gave much higher levels of GerRB-SGFP in spores, and the protein was clearly in one or multiple foci in $\sim 85 \%$ spores. In addition, a plasmid carrying gerD plus its promoter fused to a gene encoding the mScarlet-I red fluorescent protein also gave spores with red foci in all spores, consistent with this protein also being localized in germinosomes in B. cereus spores.

\section{Results}

\subsection{Visualization of Germinant Proteins in a Germinosome in B. cereus Dormant Spores}

B. cereus strains were constructed which expressed either the GerRB protein or all GerR proteins fused with strongly enhanced green fluorescent protein (SGFP2) at the GerRB C-terminus (Table 1). Note that a study of the topology of a B. anthracis GR B subunit found that this protein's C-terminus was inside the spore's IM [27]. A series of pHT315 recombinant plasmids and pHT315-derived $B$. cereus strains were constructed and their proper construction was confirmed using restriction enzyme digestion and colony PCR (Figure 1; Figure S1). The strategy involved cloning the promoter sequence of the gerR operon (Figure S2) upstream of the entire gerRB coding sequence without its stop codon and followed by a small-region coding for a linker and then the SGFP2 gene. The high level GerRB-fusion protein expression would allow competition for presumed binding sites in the spore for native GerRB protein expressed from the chromosome. As controls, strains carrying plasmids either with expression of SGFP2 protein alone controlled by the constitutive promoter of the $\operatorname{aph} A 3^{\prime}$ (aminoglycoside phosphotransferase A3') gene or with the empty vector pHT315 were constructed, as was a strain with a gerRB-SGFP2 but no promoter. An additional pHT315 plasmid was constructed in which the entire gerR operon was under PgerR control, with gerRB fused to SGFP2. With this construct, the polycistronic gerR mRNA would promote translational coupling between gerRA, gerRC and gerRB-SGFP2, and thus GerRB-SGFP2 is more likely to be incorporated into a GR than if it were translated alone. Indeed, GR subunits translated alone have been found to be rather unstable [28]. One final plasmid was constructed in which gerD and its promoter were fused to the $m S$ carlet-I gene; note that based on results in B. subtilis, the gerD promoter is likely stronger than the gerR operon's promoter [29].

Table 1. Strains used in this study.

\begin{tabular}{ccc}
\hline Strains. & Genotype & Sources \\
\hline E. coli DH5 $\alpha$ & F-endA1 hsdR $(r k$ - mk+) supE44 thi-1 recA1 gyrA96 relA1 & lab stock \\
B. cereusATCC14579 & B. cereus wild-type & lab stock \\
B. cereus 001 & B. cereus carrying pHT315 Ery & this study \\
B. cereus 002 & B. cereus carrying pHT315-PaphA3'-SGFP2 Ery ${ }^{\mathrm{r}}$ & this study \\
B. cereus 003 & B. cereus carrying pHT315-PgerR-gerRB-SGFP2 Ery & this study \\
B. cereus 004 & B. cereus carrying pHT315-gerRB-SGFP2 Ery & this study \\
B. cereus 005 & B. cereus carrying pHT315-PgerR-SGFP2 Ery & this study \\
B. cereus 006 & B. cereus carrying pHT315-PgerR-gerR-SGFP2 Ery ${ }^{\mathrm{r}}$ & this study \\
B. cereus 007 & B. cereus carrying pHT315-PgerD-gerD-mScarlet-I Ery & this study \\
\hline
\end{tabular}




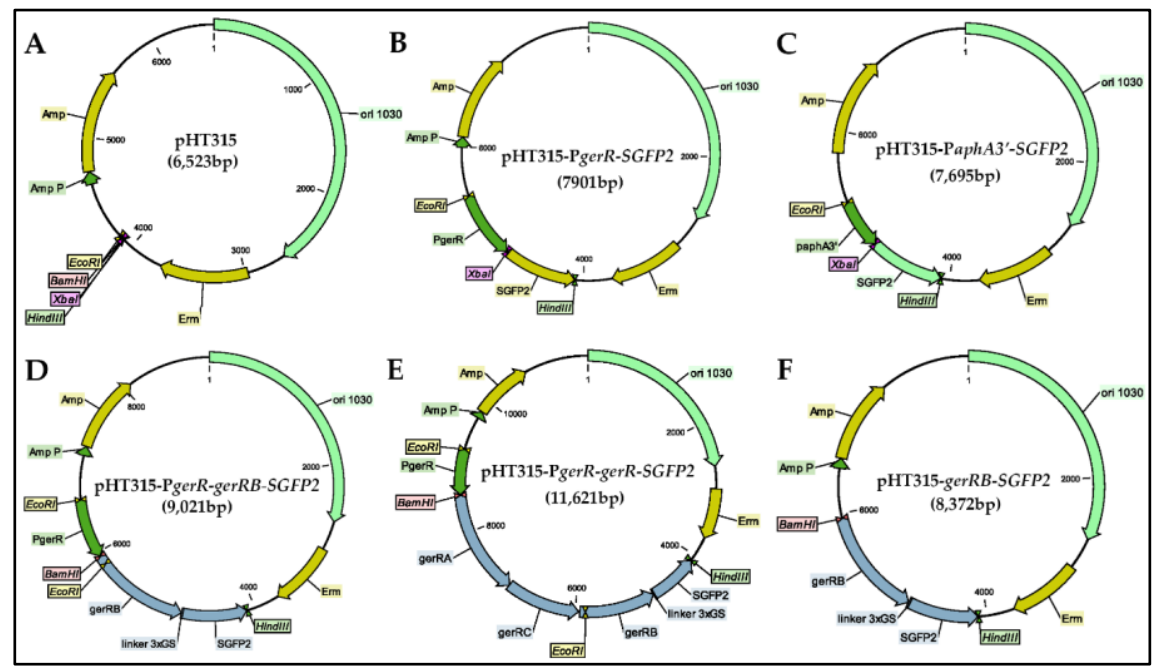

Figure 1. Schematic diagram of the recombinant plasmids. (A) pHT315; (B) pHT315-PgerR-SGFP2; (C) pHT315-PaphA3'-SGFP2; (D) pHT315-PgerR-gerRB-SGFP2; (E) pHT315-PgerR-gerR-SGFP2; (F) pHT315-gerRB-SGFP2.

To examine the expression of the fusion proteins in spores, freshly sporulated B. cereus spores were purified and analyzed by fluorescence microscopy. The maximum and integrated fluorescence intensity of 228 individual spores was measured using ImageJ software. The results indicated that the maximum and integrated intensities from spores carrying the GerRB-SGFP2 and GerR-SGFP2 fusion proteins expressed from genes under gerR control were both significantly higher than values for the wild-type spores and spores carrying pHT315. Note that there seems less general diffuse fluorescence if the entire operon is expressed (compare Figure 2H,J) corroborating better germinosome localization of GerRB-SGFP2 upon co-expression. Results obtained for spores carrying the GerD-mScarlet-I fusion protein under gerD control were in line with the GerRB-SGFP2 data though the areas of high fluorescence in the spores vary somewhat morphologically (Figure 3). The spores carrying pHT315 also showed significantly lower fluorescence maximum intensity than wild-type spores (Figure 3A), but there was no significant difference in these spores' integrated fluorescence intensity (Figure 3B). However, the maximum and integrated fluorescence intensity of spores carrying pHT315-PgerR-gerRB-SGFP2 were significantly higher than in spores carrying pHT315-gerRB-SGFP2 with no gerR promoter (Figure 3). We then quantified the number of bright spots or foci, which we have designated as germinosomes (Figure 4). As is shown, such structures were visualized in some individual spores obtained from cells carrying plasmids with gerRB-SGFP2. When a total of 2075 spores were analyzed in three separate experiments (516, 792 and 767 spores), this analysis showed that the germinosome was present in $32 \%$ of spores carrying pHT315-PgerR-gerRB-SGFP2 (Figure 4). A total of 915 spores carrying the entire gerR operon with gerRB fused to SGFP2 were analyzed; this analysis showed that one and two germinosomes were present in $71 \%$ and $14 \%$ of the spores carrying pHT315-PgerR-gerR-SGFP2, respectively (Figure 4) A total of 750 spores carrying pHT315-PgerD-gerD-mScarlet-I were also analyzed; this analysis showed that one, two and three germinosomes were present in 36\%,37\% and 27\%, respectively, of the spores (Figures 2, 4 and 5E). Notably, in B. subtilis spores, initial visualization of the germinosome was hampered by high autofluorescence from coat proteins [29-31], but B. cereus spore coat protein autofluorescence seems much lower. 


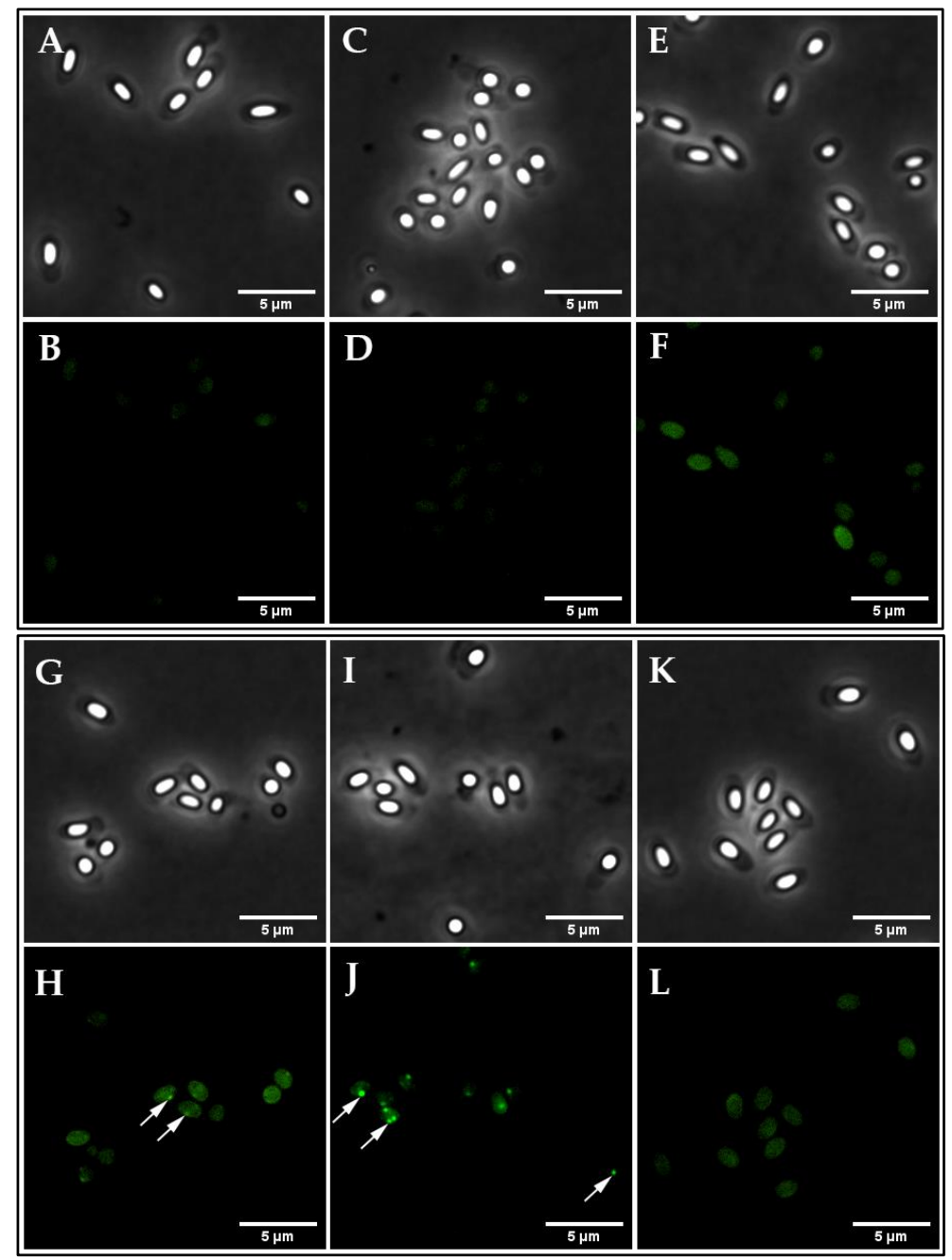

Figure 2. Visualization of the GerRB-SGFP2 germinosome in B. cereus dormant spores. Phase-contrast $(\mathbf{A}, \mathbf{C}, \mathbf{E}, \mathbf{G}, \mathbf{I}, \mathbf{K})$ and fluorescence microscopy images $(\mathbf{B}, \mathbf{D}, \mathbf{F}, \mathbf{H}, \mathbf{J}, \mathbf{L})$ of dormant spores harboring various plasmids including: (A,B) wild-type spores; (C,D) spores carrying pHT315; (E,F) spores carrying pHT315-PaphA3'-SGFP2; (G,H) spores carrying pHT315-PgerR-gerRB-SGFP2; (I,J) spores carrying pHT315-PgerR-gerR-SGFP2; (K,L) spores carrying pHT315-gerRB-SGFP2 (no gerR promoter). Images were captured with a PH3 channel exposure time of $200 \mathrm{~ms}$ and an excitation channel at $470 \mathrm{~nm}$ using $10 \%$ laser power with an exposure time of $2 \mathrm{~s}$ The white arrows indicate some of the likely germinosomes in spores, and note the large heterogeneity in their fluorescence intensity. All panels are at the same magnification, and the scale bar is $5 \mu \mathrm{m}$. 


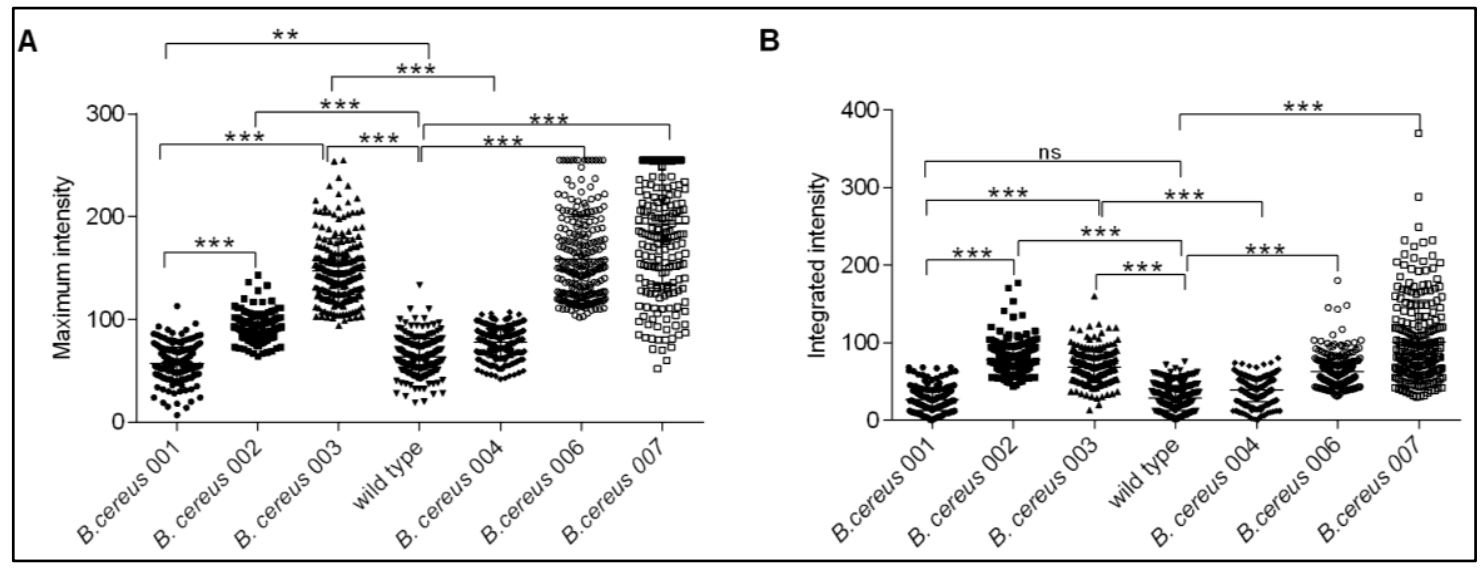

Figure 3. Analysis of the fluorescence intensity and calculations of fluorescence in individual B. cereus spores of strains numbered as in Table 1. (A) Maximum fluorescence intensity in dormant spores of various strains; (B) Integrated fluorescence intensity in dormant spores of various strains. ns: not significant, $^{* *}: p<0.01$ and ${ }^{* * *}: p<0.001$. Note that in figure A the apparent dark bar at the top of the data for strain B. cereus 007 reflects a large number of overlapping individual points.

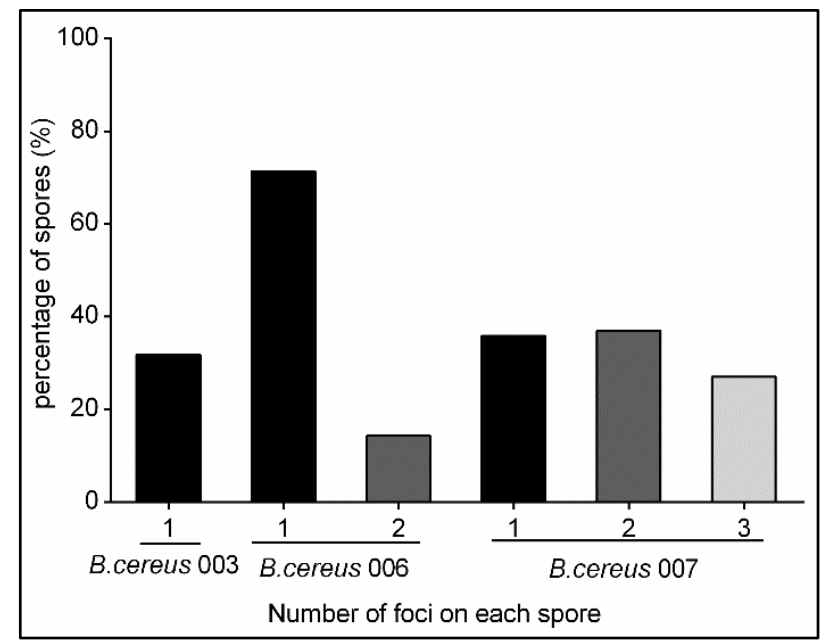

Figure 4. Percentage of germinosomes in dormant spores of B. cereus 003, B. cereus 006 and B. cereus 007. The germinosome in individual B. cereus 003 spores carrying pHT315-PgerR-gerRB-SGFP2, B. cereus 006 spores carrying pHT315-PgerR-gerR-SGFP2 and B. cereus 007 spores carrying pHT315-PgerD-gerD-mScarlet-I were distinguished from the background fluorescence during the calculation process. 


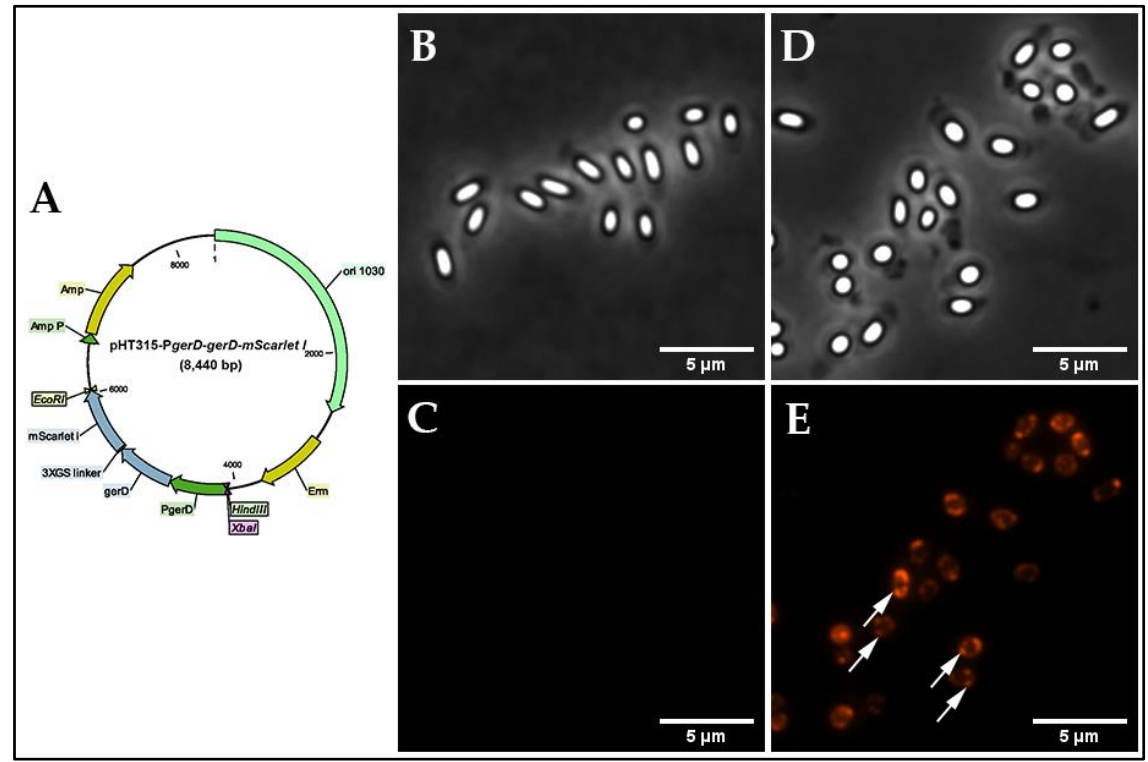

Figure 5. Construction of B. cereus 007 and visualization of GerD-mScarlet-I in dormant spores. (A), schematic diagram of plasmid pHT315-PgerD-gerD-mScarlet-I. phase-contrast (B,D) and fluorescence microscopy images $(\mathbf{C}, \mathbf{E})$ of $\mathbf{B}$. cereus dormant spores: $(\mathbf{B}, \mathbf{C})$ wild-type spores and $(\mathbf{D}, \mathbf{E})$ spores carrying pHT315-PgerD-gerD-mScarlet-I. The white arrows indicate GerD in germinosomes. All panels are at the same magnification, and the scale bar is $5 \mu \mathrm{m}$.

\subsection{Validation that All Spores Carry Plasmids}

One concern in using a plasmid-encoded fusion protein gene to visualize potential germinosomes in spores, is that plasmid partition at the sporulation division may or may not be $100 \%$ [32-34]. Consequently, many spores from plasmid-carrying cells may not carry the gene for the fusion protein. To examine this possibility, 24 colonies, each generated by single spores obtained from B. cereus cells carrying pHT315-PgerR-gerRB-SGFP2, were examined on TSB-agar plates containing $10 \mu \mathrm{g} / \mathrm{mL}$ erythromycin, and all grew. In addition, the expected DNA fragment of PgerR-gerRB-SGFP2 was amplified successfully from 24 spore-derived colonies of B. cereus strain 003 carrying PHT315-PgerR-gerRB-SGFP2 (Figure 6). These results indicate that all dormant spores obtained from B. cereus cells carrying pHT315-PgerR-gerRB-SGFP2 retained at least one copy of the plasmid.

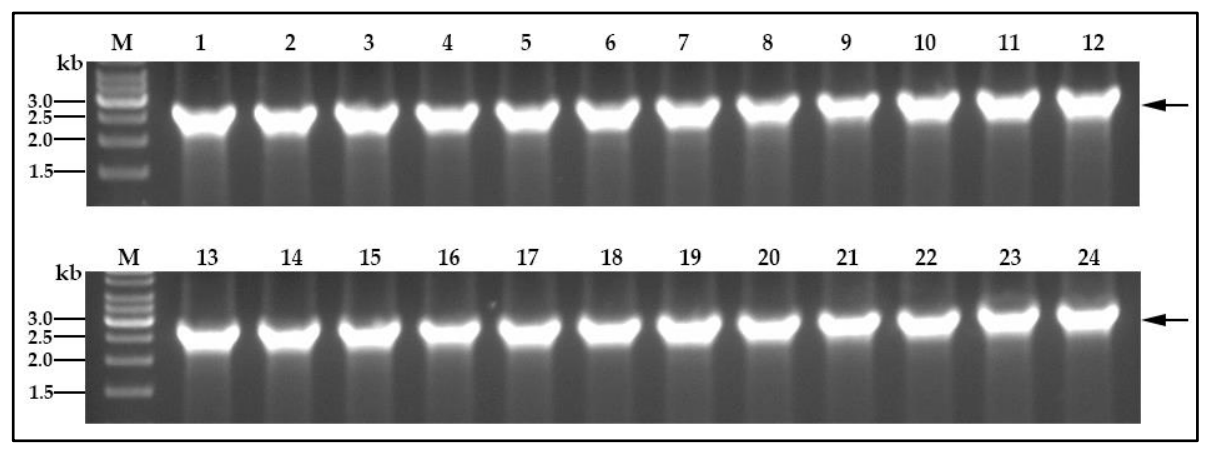

Figure 6. Confirmation that all germinated spores carry pHT315-PgerR-gerRB-SGFP2. Colony PCR was carried out on 24 independent colonies from individual spores of B. cereus 003 carrying pHT315-PgerR-gerRB-SGFP2, as described in Methods. Lanes are: M, GeneRuler $1 \mathrm{~kb}$ DNA ladder (Thermo Fisher Scientific); 1-24, PCR from B. cereus 003 carrying pHT315-PgerR-gerRB-SGFP2. The black arrow indicates the DNA fragment of PgerR-gerRB-SGFP2. 


\subsection{Confirmation of Fusion Protein GerRB-SGFP2 Expression in B. cereus Dormant Spores}

We designed pHT315-derived B. cereus strains to visualize the GerR B-subunit fused to a GFP-reporter and under the control of the promoter of the gerR operon. The fusion protein contained a flexible linker between the gerRB and SGFP2 genes and lacked the gerRB stop codon. western blotting with anti-GFP antibody detected the GerRB-SGFP2 fusion protein at the expected size of $69 \mathrm{kDa}$ in extracts from spores carrying pHT315-PgerR-gerRB-SGFP2, but not SGFP2 alone, while bands corresponding to the size of GerRB-SGFP2 protein were not detected in extracts from wild-type spores or spores carrying pHT315 or pHT315-gerRB-SGFP2 (Figure 7). This indicated that the GerRB protein fused to the SGFP2 protein was expressed under the control of the gerR operon promoter. A nonspecific $100 \mathrm{kDa}$ protein in extracts of all spores also cross-reacted with the polyclonal antibodies used, as did a protein of $\sim 55 \mathrm{kDa}$.

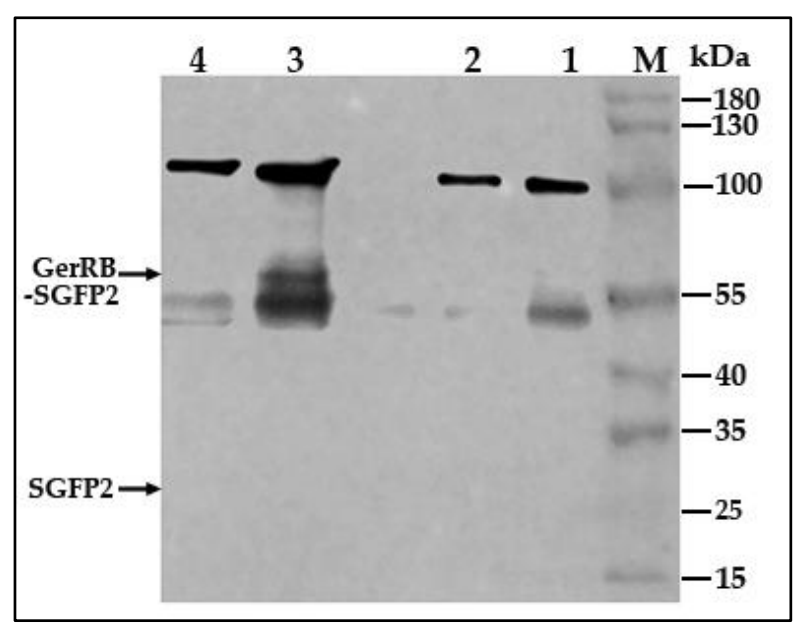

Figure 7. Analysis of GerRB-SGFP2 fusion protein expression in B. cereus spores of various strains. thirty micrograms protein in extracts from dormant spores of various B. cereus strains were separated on a $10 \%$ SDS-PAGE gel and western blots were probed with rabbit polyclonal anti-GFP antibody as described in Methods. The black arrow indicates the position of the expected 69 kDa GerRB-SGFP2 protein. Two nonspecific bands of $\sim 100 \mathrm{kDa}$ and $\sim 55 \mathrm{kDa}$ were also detected in all extracts. Notably, free SGFP2 at $27 \mathrm{kDa}$ was not detected, in particular in extracts of spores carrying pHT315- PgerR-gerRB-SGFP2. The extracts run in the various lanes were from: lane 1, wild-type spores; lane 2, spores carrying pHT315; lane 3, spores carrying pHT315-PgerR-gerRB-SGFP2; lane 4, spores carrying pHT315-gerRB-SGFP2; lane $\mathrm{M}$, prestained protein ladder.

\section{Discussion}

Bacillus cereus spores consist of a core with the genetic material surrounded by the protective layers including the IM, a peptidoglycan containing cortex, the proteinaceous coat and the exosporium. Together they provide the spore with extreme resistance. In addition, activation of GRs in the spore's IM is likely the first event in germination induced by physiological germinants.

Single or double crossovers and overexpression can all be used to fuse a target gene in a bacterial chromosome to the $g f p$ reporter gene. Ideally, a double crossover would be used to do this. However, we found that a recombinant plasmid (Figure S3) that would theoretically integrate gerRB-SGFP2 at the chromosomal gerRB gene did not integrate into the B. cereus chromosome. Therefore, we generated the fusion gene gerRB-SGFP2 on the low copy number episomal plasmid pHT315, where expression could be driven by the native promoter of the gerR operon. This vector was previously reported to localize the gerP operon to the inner coat of $B$. cereus spores and the protein IlsA (iron-regulated leucine rich surface protein) to the bacterial surface of B. cereus [35,36]. While this may cause an imbalance in levels of GR subunits which normally are in a 1:1:1 ratio, the higher amount of the 
GerRB-SGFP2 fusion protein may help GerRB-SGFP2 compete more effectively with wild-type GerRB for association with GerRA and GerRC, as intact GR formation in B. subtilis requires all 3 subunits.

Previous studies have shown that the B. subtilis gerA operon and the B. cereus gerR operon are expressed in developing forespores, and the products are involved in spore germination with L-alanine $[23,24]$. In our study, the primary objective was to ascertain whether the GerRB-SGFP2 fusion protein can be visualized and localized in B. cereus dormant spores, and our work showed that what is almost certainly a germinosome can be visualized by its GerRB-SGFP2 fluorescence in almost a third of $B$. cereus spores (Figure $2 \mathrm{H}$ ). However, the $\sim 30 \%$ of $B$. cereus spores exhibiting a germinosome was much lower than that for germinosomes in $B$. subtilis spores $[25,26,29]$. Reasons for this large difference in apparent levels of germinosomes are not clear, but there are a number of possibilities including the following. (1) While all spores from cells carrying pHT315-PgerR-gerRB-SGFP2 contained at least one plasmid copy, perhaps the actual copy number was very heterogeneous such that $\sim 70 \%$ of spores had so few plasmid copies such that insufficient GerRB-SGFP2 was made to compete effectively with wild-type GerRB in GR and germinosome formation. (2) It is known that GR levels in individual spores of at least B. subtilis are quite heterogeneous, most likely for stochastic reasons [29,37], and perhaps plasmid-driven GerRB-SGFP2 levels can only compete effectively for GR and germinosome incorporation in spores with low wild type GerRB levels. In terms of possibilities 1 and 2, it is notable that expression of SGFP2 alone from the gerR promoter gave very heterogeneous levels of GFP fluorescence in individual spores (Figure S2), although the precise causes of this heterogeneous expression are not clear. (3) When the enteric bacterium Escherichia coli is used to express recombinant or heterologous protein, the protein synthesized is sometimes aggregated perhaps because high levels of the recombinant protein synthesized interfere with protein folding [38]. This may be a particular problem for GerRB which is most likely normally co-translated with the other two GR subunits and these may all fold together. However, this may not take place efficiently with plasmid-encoded GerRB, which may be very unstable in the absence of the other GerR subunits. This could greatly decrease the efficiency of GerRB-SGFP2 incorporation into a germinosome in some developing spores. Indeed, the much greater levels of GerRB-SGFP2 and fluorescent germinosomes in spores carrying the whole gerR operon with gerRB-fused to SGFP2 strongly suggests that GerRB-SGFP2 instability when expressed alone is most likely a major reason for the low levels of germinosomes in spores only expressing this one GerR subunit. However, the obvious heterogeneity in levels of fluorescence intensities with GerRB-SGFP2, GerR-SGFP2 or GerD-mScarlet-I fusions suggests that heterogeneity in levels of plasmids or GR expression may contribute to this heterogeneity as well.

In conclusion we found that we expressed the GerRB-SGFP2 and GerR-SGFP2 fusion protein driven by the gerR operon promoter and the GerD-mScarlet-I fusion protein driven by the gene gerD promoter with plasmid to visualize germinosomes and indeed confirmed the existence of germinosomes in B. cereus spores for the first time. Our findings lay the groundwork for further research on visualizing the behavior of GR in B. cereus spores.

\section{Materials and Methods}

\subsection{Growth of Bacterial Strains}

The strains used in this study are listed in Table 1. E. coli DH5 $\alpha$ was grown in Lysogeny broth (LB) medium at $37^{\circ} \mathrm{C}$. B. cereus strains were grown at $30^{\circ} \mathrm{C}$ in trypticase soy broth (TSB) medium. When needed, $100-\mu \mathrm{g} / \mathrm{mL}$ ampicillin or $10-\mu \mathrm{g} / \mathrm{mL}$ erythromycin (Sigma-Aldrich Chemie B. V. The Netherlands) was used.

\subsection{Isolation of B. cereus ATCC 14579 Genomic DNA}

Genomic DNA of B. cereus ATCC 14579 was isolated using a modified method from Henderson [39]. Briefly, a single colony was incubated overnight in TSB medium at $30^{\circ} \mathrm{C}$ and $200 \mathrm{rpm}$, centrifuged for 5 min at 12,000 rpm, suspended in the resuspension solution with RNase A (ThermoFisher Scientific, 
The Netherlands), lysozyme added to $0.2 \mathrm{mg} / \mathrm{mL}$ (Sigma-Aldrich Chemie B. V. The Netherlands), and the mix was incubated for $1 \mathrm{~h}$ at $37^{\circ} \mathrm{C}$. The suspension was then heated for $5 \mathrm{~min}$ at $60^{\circ} \mathrm{C}$, pre-warmed $\left(60^{\circ} \mathrm{C}\right)$ sodium dodecyl sulfate (SDS) solution was added to $1 \%(w / v)$ (Sigma Aldrich Chemie B. V. The Netherlands), and the lysate was extracted twice by phenol:chloroform:isoamyl alcohol (25:24:1, pH 6.6) (Fisher Scientific B. V. The Netherlands). The upper phase was carefully transferred to a new $2 \mathrm{~mL}$ tube, three volumes of absolute ethanol was added and mixed by inverting. Genomic DNA was collected, washed $5 \mathrm{~min}$ with $70 \%(v / v)$ ethanol, dried $10 \mathrm{~min}$ at room temperature, dissolved in sterile Milli-Q water and used as a PCR template.

\subsection{Construction of Recombinant Plasmids}

The recombinant plasmids used in this study are listed in Table 2. All primers used are listed in Table S1. The $676 \mathrm{bp}$ long gerRB promoter region (PgerR) upstream of the gerR operon was PCR amplified from $B$. cereus ATCC 14579 genomic DNA using a pair of primers P_RB-F/P_RB-R. The nucleotide sequence of the gerRB (BC_0782) gene was PCR amplified from B. cereus ATCC 14579 genomic DNA using primers RB-F/RB-fuse-GFP-R introducing a flexible linker (GSGSGS) [40]. The fragment of SGFP2 was PCR amplified from plasmid pSGFP2-C1 using primers RB-fuse-GFP-F/GFP-R containing a flexible linker encoding the protein sequence GSGSGS. The purified DNA fragment of PgerR was sub-cloned into $E c o R$ I and BamH I sites of the shuttle vector pHT315 (Figure 1A), resulting in the pHT315-PgerR vector. The SGFP2 gene was PCR amplified from plasmid pSGFP2-C1 using primers GFP-F/GFP-R, the purified DNA fragment of the SGFP2 gene sub-cloned into Xba I and Hind III sites of pHT315-PgerR, resulting in pHT315-PgerR-SGFP2 (Figure 1B). The purified DNA fragments of gerRB and SGFP2 were fused by two-step fusion PCR, the fusion fragment gerRB-SGFP2 was sub-cloned into BamH I and Hind III sites of pHT315-PgerR vector, resulting in pHT315-PgerR-gerRB-SGFP2 (Figure 1D). The negative control plasmid pHT315-gerRB-SGFP2 was constructed by sub-cloning the fusion fragment gerRB-SGFP2 into BamH I and Hind III sites of the pHT315 vector (Figure 1F). As a positive control plasmid, the SGFP2 gene alone was PCR amplified from plasmid pSGFP2-C1 using primers GFP-F/GFP-R, and then the gfpmut1 gene of vector pHT315-PaphA3'-gfp [35] was replaced by the purified DNA fragment of the SGFP2 gene between Xba I and Hind III sites, resulting in pHT315-PaphA3'-SGFP2 (Figure 1C). The nucleotide sequence of the gerRA (BC_0784) and gerRC (BC_0783) genes was PCR amplified from B. cereus ATCC 14579 genomic DNA using primers RA-F/AC-fuse-B-R. The gerRB-SGFP2 fusion fragment was PCR amplified from plasmid pHT315-gerRB-SGFP2 using primers AC-fuse-B-F/GFP-R. Then, these two purified DNA fragments were fused by two-step fusion PCR, the fusion fragment gerR-SGFP2 was sub-cloned into BamH I and Hind III sites of the pHT315-PgerR vector, resulting in pHT315-PgerR-gerR-SGFP2 (Figure 1E). The nucleotide sequence of the $606 \mathrm{bp}$ long gerD gene promoter (PgerD) plus the gerD coding gene (BC_0169) was PCR amplified from B. cereus ATCC 14579 genomic DNA using primers P_D_F/D-fuse-mSi-R. The $m$ Scarlet-I gene was PCR amplified from plasmid pEB2-mScarlet-I using primers D-fuse-mSi-F/mSi-R. Then these two purified DNA fragments were fused by two-step fusion PCR, the fusion fragment PgerD-gerD-mScarlet-I was sub-cloned into $\mathrm{Xba}$ I and EcoR I sites of the pHT315 vector, resulting in pHT315-PgerD-gerD-mScarlet-I (Figure 5A). The correct construction of all recombinant plasmids was confirmed using double restriction enzyme digestion and DNA sequencing (Macrogen Europe B. V. The Netherlands). 
Table 2. Plasmids used in this study.

\begin{tabular}{|c|c|c|}
\hline Plasmids & Genotype or Description & Sources \\
\hline pSGFP2-C1 & source of the SGFP2 gene $\mathrm{Kan}^{\mathrm{r}}$ & lab stock \\
\hline pEB2-mScarlet-I & source of the mScarlet-I gene Kan ${ }^{r}$ & lab stock \\
\hline pHT315 & a B. thuringiensis/E. coli shuttle vector Amp ${ }^{r}$ Ery $^{r}$ & [35] \\
\hline pHT315-PaphA3'-gfp & $\begin{array}{l}\text { expression of gfpmut1 controlled by the constitutive } \\
\text { PaphA3' promoter Amp }{ }^{\mathrm{r}} \text { Ery }{ }^{\mathrm{r}}\end{array}$ & {$[35]$} \\
\hline pHT315-PgerR-SGFP2 & $\begin{array}{l}\text { expression of SGFP2 was controlled by the promoter of the } \\
\text { gerR operon Amp }{ }^{r} \text { Ery }^{r}\end{array}$ & this study \\
\hline pHT315-PaphA3'-SGFP2 & $\begin{array}{l}\text { expression of SGFP2 was controlled by the constitutive } \\
\text { PaphA3' promoter Amp }{ }^{\mathrm{r}} \text { Ery }^{\mathrm{r}}\end{array}$ & this study \\
\hline pHT315-PgerR-gerRB-SGFP2 & $\begin{array}{l}\text { expression of GerRB-SGFP2 was controlled by the promoter of } \\
\text { the gerR operon Amp }{ }^{r} \text { Ery }{ }^{r}\end{array}$ & this study \\
\hline pHT315-gerRB-SGFP2 & no promoter - a negative control Amp ${ }^{\mathrm{r}}$ Ery ${ }^{\mathrm{r}}$ & this study \\
\hline pHT315- PgerR-gerR-SGFP2 & $\begin{array}{l}\text { expression of GerRB-SGFP2 was controlled by the promoter of } \\
\text { the gerR operon Amp }{ }^{\mathrm{r}} \text { Ery }{ }^{\mathrm{r}}\end{array}$ & this study \\
\hline pHT315-PgerD-gerD-mScarlet-I & $\begin{array}{l}\text { expression of GerD-mScarlet-I was controlled by the gerD } \\
\text { promoter Amp }{ }^{\mathrm{r}} \text { Ery }^{\mathrm{r}}\end{array}$ & this study \\
\hline
\end{tabular}

\subsection{Preparation of Electro-Competent Cells}

B. cereus ATCC 14579 cells were cultured overnight in $5 \mathrm{~mL}$ TSB medium at $37^{\circ} \mathrm{C}$ and $200 \mathrm{rpm}$. One milliliter of the overnight culture was re-inoculated in $100 \mathrm{~mL}$ fresh TSB medium and incubated at $37^{\circ} \mathrm{C}$ and $200 \mathrm{rpm}$ until reaching an optical density at $600 \mathrm{~nm}$ (OD600) of 0.2-0.3. Cells were washed five times using ice cold electroporation buffer (250-mM sucrose, 1-mM HEPES, 1- $\mathrm{mM} \mathrm{MgCl}_{2}$ and $10 \%$ glycerol, $\mathrm{pH}$ 7.0), concentrated 150 -fold and $50 \mu \mathrm{L}$ aliquots were stored at $-80^{\circ} \mathrm{C}$ until use.

\subsection{Electroporation}

Plasmids pHT315-PgerR-SGFP2， pHT315-PgerR-gerRB-SGFP2， pHT315-gerRB-SGFP2, pHT315-PaphA3'-SGFP2, pHT315-PgerR-gerR-SGFP2, pHT315-PgerD-gerD-mScarlet-I and pHT315 (Table 2) were introduced into wild-type B. cereus competent cells via electroporation, which is performed based on Nathalie's method [41]. Briefly, $50 \mu \mathrm{L}$ of B. cereus competent cells were thawed on ice, $500 \mathrm{ng}$ plasmid DNA was added, and the mixture was incubated on ice for $5 \mathrm{~min}$. The mixture was transferred into ice-cold $1 \mathrm{~mm}$ gap PulseStar electroporation cuvettes (Westburg, The Netherlands, Cat No.: WB 1-4110), and electroporation was performed at $2 \mathrm{kV}$ and $4 \mathrm{~ms}$ using a MicroPulser ${ }^{\mathrm{TM}}$ electroporation apparatus (Bio-Rad, The Netherlands). After electroporation, $1 \mathrm{~mL}$ TSB medium was immediately added to the cells and incubated at $37^{\circ} \mathrm{C} 200 \mathrm{rpm}$ for $1.5 \mathrm{~h}$. The transformation mixture was plated on tryptic soy agar with $10 \mu \mathrm{g} / \mathrm{mL}$ erythromycin and incubated overnight at $30{ }^{\circ} \mathrm{C}$. The following day an erythromycin-positive single colony was analyzed by colony PCR using sequencing primers $315-\mathrm{F} / 315-\mathrm{R}$.

\subsection{Preparation of Dormant Spores}

Sporulation of B. cereus strains used in this study was carried out a chemically defined growth and sporulation (CDGS) medium [42], which contained the following components (final concentrations): D-glucose $(10 \mathrm{mM})$, L-glutamic acid $(20 \mathrm{mM})$, L-leucine $(6 \mathrm{mM}), \mathrm{L}$-valine $(2.6 \mathrm{mM}), \mathrm{L}$-threonine $(1.4 \mathrm{mM})$, L-methionine $(470 \mu \mathrm{M})$, L-histidine $(320 \mu \mathrm{M})$, DL-lactate sodium $(5 \mathrm{mM})$, acetic acid $(1 \mathrm{mM})$, $\mathrm{FeCl}_{3} \cdot 6 \mathrm{H}_{2} \mathrm{O}(50 \mu \mathrm{M}), \mathrm{CuCl}_{2} \cdot 2 \mathrm{H}_{2} \mathrm{O}(2.5 \mu \mathrm{M}), \mathrm{ZnCl}_{2}(12.5 \mu \mathrm{M}), \mathrm{MnSO}_{4} \cdot \mathrm{H}_{2} \mathrm{O}(66 \mu \mathrm{M}), \mathrm{MgCl}_{2} \cdot 6 \mathrm{H}_{2} \mathrm{O}$ $(1 \mathrm{mM}),\left(\mathrm{NH}_{4}\right)_{2} \mathrm{SO}_{4}(5 \mathrm{mM}), \mathrm{Na}_{2} \mathrm{MoO}_{4} \cdot 2 \mathrm{H}_{2} \mathrm{O}(2.5 \mu \mathrm{M}), \mathrm{CoCl}_{2} \cdot 6 \mathrm{H}_{2} \mathrm{O}(2.5 \mu \mathrm{M})$ and $\mathrm{Ca}\left(\mathrm{NO}_{3}\right)_{2} \cdot 4 \mathrm{H}_{2} \mathrm{O}$ $(1 \mathrm{mM})$. The CDGS medium was buffered to $\mathrm{pH} 7.2$ with $100 \mathrm{mM}$ potassium phosphate buffer. As previous described [43], a single colony of $B$. cereus was incubated in $5 \mathrm{~mL}$ TSB medium (TSB medium for pHT315-derived B. cereus strains had $10 \mu \mathrm{g} / \mathrm{mL}$ erythromycin) at $30{ }^{\circ} \mathrm{C}$ and $200 \mathrm{rpm}$ overnight. Then, $200 \mu \mathrm{L}$ of the overnight culture was transferred into $20 \mathrm{~mL}$ fresh TSB medium (TSB medium for $\mathrm{pHT} 315-$ derived B. cereus strains had $10 \mu \mathrm{g} / \mathrm{mL}$ erythromycin) and grown at $30^{\circ} \mathrm{C}$ 
and $200 \mathrm{rpm}$ until the OD600 was 0.5. The cells were harvested by centrifugation at $5000 \mathrm{rpm}$ for $15 \mathrm{~min}$ and suspended in $250 \mathrm{~mL}$ CDGS medium (CDGS medium for pHT315-derived B. cereus strains had $10 \mu \mathrm{g} / \mathrm{mL}$ erythromycin). Finally, the culture was incubated at $30^{\circ} \mathrm{C}$ and $200 \mathrm{rpm}$ for $5 \mathrm{~d}$. Spores were harvested, washed three times with pre-cooled phosphate buffered saline (PBS, pH 7.4) (Thermofisher Scientific, Eindhoven, The Netherlands). After harvesting, the spores were further purified by centrifugation through HistodenZ (Sigma Aldrich Chemie B.V., Zwijndrecht, The Netherlands) as follows. One milliliter of spores $(\mathrm{OD} 600=100)$ were transferred to a new $1.5 \mathrm{~mL}$ centrifuge tube. After centrifuging, the spore pellet was suspended in $750 \mu \mathrm{L}$ of $16 \%$ HistodenZ which was then slowly layered on $800 \mu \mathrm{L}$ of $40 \%$ HistodenZ and centrifuged for $2 \mathrm{~h}$ at $15,000 \mathrm{rpm}$ at $4{ }^{\circ} \mathrm{C}$. After discarding the supernatant, the pelleted spores were suspended in $200 \mu \mathrm{L}$ of $16 \%$ HistodenZ which was slowly layered on $1 \mathrm{~mL}$ of $40 \%$ HistodenZ and centrifuged for $20 \mathrm{~min}$ at 15,000 rpm at $4{ }^{\circ} \mathrm{C}$. The pelleted spores were washed three times with 1-1.5 mL PBS, pH 7.4, to remove HistodenZ. The purified spores contained more than $95 \%$ phase bright spores under phase contrast microscopy and were stored at $4{ }^{\circ} \mathrm{C}$ until use.

\subsection{Image Acquisition and Analysis}

Preparation of microscope slides and imaging were carried out as described by Pandey [44]. Imaging of dormant spores was performed with a Nikon Eclipse Ti microscope equipped with phase-contrast and fluorescence components. For phase-contrast imaging, a CFI Plan Apochromat Lambda 100X Oil, ORCA-Flash 4.0 Digital CMOS camera C11440-22CU (Hamamatsu Photonics K.K, Sewickley, PA, USA), Prior Brightfield LED and Lambda 10-B shutter (Sutter Instrument, Novato, CA, USA) was equipped with NIS-elements 4.50. All microscope images were analyzed with ImageJ (http://rsbweb.nih.gov/ij), and all statistical analysis were carried out in GraphPad 6.0.

\subsection{Preparation of Protein Extracts}

Extracts of dormant spores were prepared by a published method [45,46]. Spores (OD600 = 50) were suspended in $200 \mu \mathrm{L}$ TEP buffer $(50 \mathrm{mM}$ Tris- $\mathrm{HCl} \mathrm{pH}$ 7.4, $5 \mathrm{mM}$ EDTA-dipotassium, cOmplete $^{\mathrm{TM}}$ Protease Inhibitor Cocktail (Sigma Aldrich Chemie B. V. The Netherlands), $1 \%$ Triton $X-100$ ). Extracts were generated by bead beating with six rounds of $30 \mathrm{~s}$ at $6000 \mathrm{rpm}$ with cooling on ice between each round, in a Precellys 24 tissue homogenizer (Bertin Instruments, Montigny-le-Bretonneux, France) with $800 \mathrm{mg} 0.1 \mathrm{~mm}$ diameter Zirconia/Silica beads (BioSpec Products, Bartlesville, OK, USA). Lysate samples were incubated with 1\% SDS and $150 \mathrm{mM} \beta$-mercaptoethanol (Bio-Rad Laboratories B.V., The Netherlands. Cat No.:1610710) for $2 \mathrm{~h}$ at room temperature. Samples were bead-beaten twice more for $30 \mathrm{sec}$ at 6,000 rpm to further disrupt aggregates, and $100 \mu \mathrm{L}$ more TEP buffer was added to further suspend the extracts. Finally, samples were centrifuged for $10 \mathrm{~min}$ at $15,000 \mathrm{rpm}$ and $4{ }^{\circ} \mathrm{C}$, and the supernatant fluid was saved. Protein concentrations in extracts were estimated by the Pierce ${ }^{\mathrm{TM}}$ BCA Protein Assay Kit (Thermofisher Scientific, The Netherlands, Cat. No.: 23227).

\subsection{Examination of B. cereus Strain 003 Spores for Plasmid}

Dormant spores carrying pHT315-PgerR-gerRB-SGFP2 at OD600 of 2.0 were heated 15 min at $70{ }^{\circ} \mathrm{C}$, in duplicate. The heated spores were diluted $10^{-5}$-fold in TSB medium, $100 \mu \mathrm{L}$ of diluted spores immediately spread on a TSB agar plate (TSB-agar), and the plates were incubated for $24 \mathrm{~h}$ at $30^{\circ} \mathrm{C}$. Following this incubation, 24 single colonies in each replicate were incubated on TSB-agar with $10-\mu \mathrm{g} / \mathrm{mL}$ erythromycin at $30^{\circ} \mathrm{C}$ overnight to assess erythromycin resistance plasmid presence was confirmed by colony PCR with the primers 315-F/R.

\subsection{Western Blotting}

$30 \mu \mathrm{g}$ of protein from each extract was mixed with $4 \times$ Lemmli SDS sample buffer (Alfa Aesar, The Netherlands, Cat. No.: J60015) and incubated at $65^{\circ} \mathrm{C}$ for $30 \mathrm{~min}$. The samples and PageRuler ${ }^{\mathrm{TM}}$ Plus Prestained Protein Ladder (Thermo Fisher Scientific, The Netherlands, Cat. No.: 26619) were 
loaded on a 10\% MiniPROTEAN ${ }^{\circledR}$ TGX ${ }^{\mathrm{TM}}$ Gel (Bio-Rad, Laboratories B. V., The Netherlands, Cat. No.: 4561034) and separated for $1 \mathrm{~h}$ at 180V. Proteins were transferred to a $0.45-\mu \mathrm{m}$ PVDF membrane by wet electro-blotting for $40 \mathrm{~min}$ at $100 \mathrm{~V}$ (Bio-Rad, Laboratories B.V., The Netherlands.). The PVDF membrane was blocked with $5 \%$ skim milk for $1 \mathrm{~h}$ at room temperature and incubated with the rabbit polyclonal anti-GFP antibody at a 1:2500 dilution (abcam, ab290) in PBST (PBS with 0.1\% Tween-20) with $1 \%$ BSA (Bovine Serum Albumin, Sigma-Aldrich Chemie B. V. The Netherlands) overnight at $4{ }^{\circ} \mathrm{C}$. The membrane was washed with TBST (Tris-buffered saline with $0.1 \%$ Tween-20, pH 7.4) five times for 10 min each and incubated with HRP-conjugated goat anti-rabbit IgG H\&L at a 1:5000 dilution (abcam, ab205718) in PBST with 1\% BSA for $1 \mathrm{~h}$ at room temperature, and the membrane was washed with TBST five times for $10 \mathrm{~min}$ each. The membrane was then incubated with EZ-ECL substrate solutions (Biological Industries, Cromwell, CT, USA, Cat. No.: 20-500-120) for $2 \mathrm{~min}$ at room temperature and detected for 10 min using an Odyssey Fc Imaging system (LICOR, Lincoln, NE, USA).

Supplementary Materials: The following are available online at http://www.mdpi.com/1422-0067/21/15/5198/s1.

Author Contributions: Conceptualization, S.B.; methodology, S.B. and Y.W.; formal analysis, S.B. and Y.W.; investigation, S.B., Y.W., R.d.B., N.V., P.S. and P.v.H.; data curation, S.B. and Y.W.; writing-original draft preparation, Y.W.; writing-review and editing, S.B., P.S., Y.W. and R.d.B.; visualization, S.B. and Y.W.; supervision, S.B.; project administration, S.B. All authors have read and agreed to the published version of the manuscript.

Funding: This research received no external funding.

Acknowledgments: We acknowledge the Van Leeuwenhoek Center for Advanced Microscopy (LCAM) of the University of Amsterdam for use of microscopes. We appreciate Didier Lereclus of the Micalis Institute (INRA,

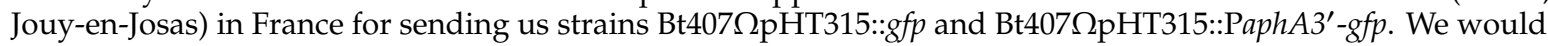
also like to thank Juan Wen for help with microscopy. Finally, Y.W. acknowledges the China Scholarship Council for her PhD scholarship.

Conflicts of Interest: The authors declare no conflicts of interest.

\section{Abbreviations}

$\begin{array}{ll}\text { GRs } & \text { germinant receptors } \\ \text { CaDPA } & \text { calcium dipicolinic acid } \\ \text { IM } & \text { inner membrane } \\ \text { CDGS } & \text { chemically defined growth and sporulation }\end{array}$

\section{References}

1. Gopal, N.; Hill, C.; Ross, P.R.; Beresford, T.P.; Fenelon, M.A.; Cotter, P.D. The prevalence and control of Bacillus and related spore-forming bacteria in the dairy industry. Front. Microbiol. 2015, 6, 1418. [CrossRef] [PubMed]

2. Ehling-Schulz, M.; Lereclus, D.; Koehler, T.M. The Bacillus cereus group: Bacillus species with pathogenic potential. Microbiol. Spectr. 2019, 7. [CrossRef]

3. Setlow, P. Resistance of spores of Bacillus species to ultraviolet light. Environ. Mol. Mutagen. 2001, 38, 97-104. [CrossRef] [PubMed]

4. Setlow, P. Spores of Bacillus subtilis: Their resistance to and killing by radiation, heat and chemicals. J. Appl. Microbiol. 2006, 101, 514-525. [CrossRef] [PubMed]

5. Hamon, M.A.; Lazazzera, B.A. The sporulation transcription factor Spo0A is required for biofilm development in Bacillus subtilis. Mol. Microbiol. 2001, 42, 1199-1209. [CrossRef] [PubMed]

6. Wu, L.J.; Errington, J. A large dispersed chromosomal region required for chromosome segregation in sporulating cells of Bacillus subtilis. EMBO J. 2002, 21, 4001-4011. [CrossRef]

7. Glaser, P.; Sharpe, M.E.; Raether, B.; Perego, M.; Ohlsen, K.; Errington, J. Dynamic, mitotic-like behavior of a bacterial protein required for accurate chromosome partitioning. Genes Dev. 1997, 11, 1160-1168. [CrossRef]

8. Ogasawara, N.; Yoshikawa, H. Genes and their organization in the replication origin region of the bacterial chromosome. Mol. Microbiol. 1992, 6, 629-634. [CrossRef] 
9. Cowan, A.E.; Olivastro, E.M.; Koppel, D.E.; Loshon, C.A.; Setlow, B.; Setlow, P. Lipids in the inner membrane of dormant spores of Bacillus species are largely immobile. Proc. Natl. Acad. Sci. USA 2004, 101, 7733-7738. [CrossRef]

10. Setlow, P. Spore germination. Curr. Opin. Microbiol. 2003, 6, 550-556. [CrossRef]

11. Moir, A. How do spores germinate? J. Appl. Microbiol. 2006, 101, 526-530. [CrossRef] [PubMed]

12. Li, Y.; Jin, K.; Perez-Valdespino, A.; Federkiewicz, K.; Davis, A.; Maciejewski, M.W.; Setlow, P.; Hao, B. Structural and functional analyses of the N-terminal domain of the A subunit of a Bacillus megaterium spore germinant receptor. Proc. Natl. Acad. Sci. USA 2019, 116, 11470-11479. [CrossRef] [PubMed]

13. Ross, C.; Abel-Santos, E. The Ger receptor family from sporulating bacteria. Curr. Issues Mol. Biol. 2010, 12, 147-158. [PubMed]

14. Nakamura, L.K. DNA relatedness among Bacillus thuringiensis serovars. Int. J. Syst. Bacteriol. 1994, 44, 125-129. [CrossRef]

15. Logan, N.A.; Carman, J.A.; Melling, J.; Berkeley, R.C. Identification of Bacillus anthracis by API tests. J. Med. Microbiol. 1985, 20, 75-85. [CrossRef]

16. Andrew, E.; Goodwin, J.; Spencer, R., Jr.; John, M.; Grizzle, J.M.; Goldsby, M.T., Jr. Bacillus mycoides: A bacterial pathogen of channel catfish. Dis. Aquat. Org. 1994, 18, 173-179.

17. Lechner, S.; Mayr, R.; Francis, K.P.; Prüss, B.M.; Kaplan, T.; Wiessner-Gunkel, E.; Stewart, G.S.; Scherer, S. Bacillus weihenstephanensis sp. nov. is a new psychrotolerant species of the Bacillus cereus group. Int. J. Syst. Bacteriol. 1998, 48, 1373-1382. [CrossRef]

18. Nakamura, L.K. Bacillus pseudomycoides sp. nov. Int. J. Syst. Bacteriol. 1998, 48, 1031-1035. [CrossRef]

19. Jiménez, G.; Urdiain, M.; Cifuentes, A.; López-López, A.; Blanch, A.R.; Tamames, J.; Kämpfer, P.; Kolstø, A.-B.; Ramón, D.; Martínez, J.F.; et al. Description of Bacillus toyonensis sp. nov., a novel species of the Bacillus cereus group, and pairwise genome comparisons of the species of the group by means of ANI calculations. Syst. Appl. Microbiol. 2013, 36, 383-391. [CrossRef]

20. Guinebretière, M.-H.; Auger, S.; Galleron, N.; Contzen, M.; de Sarrau, B.; de Buyser, M.-L.; Lamberet, G.; Fagerlund, A.; Granum, P.E.; Lereclus, D.; et al. Bacillus cytotoxicus sp. nov. is a novel thermotolerant species of the Bacillus cereus group occasionally associated with food poisoning. Int. J. Syst. Evol. Microbiol. 2013, 63, 31-40. [CrossRef]

21. Pelczar, P.L.; Setlow, P. Localization of the germination protein GerD to the inner membrane in Bacillus subtilis spores. J. Bacteriol. 2008, 190, 5635-5641. [CrossRef] [PubMed]

22. Warda, A.K.; Xiao, Y.; Boekhorst, J.; Wells-Bennik, M.H.J.; Nierop Groot, M.N.; Abee, T. Analysis of germination capacity and germinant receptor (Sub) clusters of genome-sequenced Bacillus cereus environmental isolates and model strains. Appl. Environ. Microbiol. 2017, 83, e02490-16. [CrossRef] [PubMed]

23. Hornstra, L.M.; de Vries, Y.P.; de Vos, W.M.; Abee, T.; Wells-Bennik, M.H.J. gerR, a novel ger operon involved in L-alanine- and inosine-initiated germination of Bacillus cereus ATCC 14579. Appl. Environ. Microbiol. 2005, 71, 774-781. [CrossRef] [PubMed]

24. Hudson, K.D.; Corfe, B.M.; Kemp, E.H.; Feavers, I.M.; Coote, P.J.; Moir, A. Localization of GerAA and GerAC germination proteins in the Bacillus subtilis spore. J. Bacteriol. 2001, 183, 4317-4322. [CrossRef] [PubMed]

25. Wen, J.; Pasman, R.; Manders, E.M.M.; Setlow, P.; Brul, S. Visualization of germinosomes and the inner membrane in Bacillus subtilis spores. J. Vis. Exp. 2019. [CrossRef]

26. Breedijk, R.M.P.; Wen, J.; Krishnaswami, V.; Bernas, T.; Manders, E.M.M.; Setlow, P.; Vischer, N.O.E.; Brul, S. A live-cell super-resolution technique demonstrated by imaging germinosomes in wild-type bacterial spores. Sci. Rep. 2020, 10, 5312. [CrossRef]

27. Wilson, M.J.; Carlson, P.E.; Janes, B.K.; Hanna, P.C. Membrane topology of the Bacillus anthracis GerH germinant receptor proteins. J. Bacteriol. 2012, 194, 1369-1377. [CrossRef]

28. Moir, A.; Cooper, G. Spore germination. In The Bacterial Spore: From Molecules to Systems; Driks, A., Eichenberger, P., Eds.; ASM Press: Washington, DC, USA, 2016; ISBN 9781683670780.

29. Griffiths, K.K.; Zhang, J.; Cowan, A.E.; Yu, J.; Setlow, P. Germination proteins in the inner membrane of dormant Bacillus subtilis spores colocalize in a discrete cluster. Mol. Microbiol. 2011,81, 1061-1077. [CrossRef]

30. Ghosh, S.; Setlow, B.; Wahome, P.G.; Cowan, A.E.; Plomp, M.; Malkin, A.J.; Setlow, P. Characterization of spores of Bacillus subtilis that lack most coat layers. J. Bacteriol. 2008, 190, 6741-6748. [CrossRef]

31. Magge, A.; Setlow, B.; Cowan, A.E.; Setlow, P. Analysis of dye binding by and membrane potential in spores of Bacillus species. J. Appl. Microbiol. 2009, 106, 814-824. [CrossRef] 
32. Mason, J.M.; Setlow, P. Different small, acid-soluble proteins of the $\alpha / \beta$ type have interchangeable roles in the heat and UV radiation resistance of Bacillus subtilis spores. J. Bacteriol. 1987, 169, 3633-3637. [CrossRef] [PubMed]

33. Seyler, R.W.; Yousten, A.A.; Burke, W.F. Plasmid stability in Bacillus sphaericus 2362 during recycling in mosquito larvae. J. Invertebr. Pathol. 1991, 58, 362-366. [CrossRef]

34. Turgeon, N.; Laflamme, C.; Ho, J.; Duchaine, C. Evaluation of the plasmid copy number in B. cereus spores, during germination, bacterial growth and sporulation using real-time PCR. Plasmid 2008, 60, 118-124. [CrossRef]

35. Daou, N.; Buisson, C.; Gohar, M.; Vidic, J.; Bierne, H.; Kallassy, M.; Lereclus, D.; Nielsen-LeRoux, C. IlsA, a unique surface protein of Bacillus cereus required for iron acquisition from heme, hemoglobin and ferritin. PLoS Pathog. 2009, 5, e1000675. [CrossRef] [PubMed]

36. Ghosh, A.; Manton, J.D.; Mustafa, A.R.; Gupta, M.; Ayuso-Garcia, A.; Rees, E.J.; Christie, G. Proteins encoded by the gerP operon are localized to the inner coat in Bacillus cereus spores and are dependent on GerPA and SafA for assembly. Appl. Environ. Microbiol. 2018, 84, e00760-18. [CrossRef]

37. Ghosh, S.; Scotland, M.; Setlow, P. Levels of germination proteins in dormant and superdormant spores of Bacillus subtilis. J. Bacteriol. 2012, 194, 2221-2227. [CrossRef]

38. Baneyx, F.; Mujacic, M. Recombinant protein folding and misfolding in Escherichia coli. Nat. Biotechnol. 2004, 22, 1399-1408. [CrossRef]

39. Henderson, I.; Duggleby, C.J.; Turnbull, P.C. Differentiation of Bacillus anthracis from other Bacillus cereus group bacteria with the PCR. Int. J. Syst. Bacteriol. 1994, 44, 99-105. [CrossRef]

40. Reddy Chichili, V.P.; Kumar, V.; Sivaraman, J. Linkers in the structural biology of protein-protein interactions. Protein Sci. 2013, 22, 153-167. [CrossRef]

41. Turgeon, N.; Laflamme, C.; Ho, J.; Duchaine, C. Elaboration of an electroporation protocol for Bacillus cereus ATCC 14579. J. Microbiol. Methods 2006, 67, 543-548. [CrossRef]

42. Abhyankar, W.; Hossain, A.H.; Djajasaputra, A.; Permpoonpattana, P.; Ter Beek, A.; Dekker, H.L.; Cutting, S.M.; Brul, S.; de Koning, L.J.; de Koster, C.G. In pursuit of protein targets: Proteomic characterization of bacterial spore outer layers. J. Proteome Res. 2013, 12, 4507-4521. [CrossRef] [PubMed]

43. Ghosh, S.; Korza, G.; Maciejewski, M.; Setlow, P. Analysis of metabolism in dormant spores of Bacillus species by ${ }^{31} \mathrm{P}$ nuclear magnetic resonance analysis of low-molecular-weight compounds. J. Bacteriol. 2015, 197, 992-1001. [CrossRef] [PubMed]

44. Pandey, R.; Ter Beek, A.; Vischer, N.O.E.; Smelt, J.P.P.M.; Brul, S.; Manders, E.M.M. Live cell imaging of germination and outgrowth of individual Bacillus subtilis spores; the effect of heat stress quantitatively analyzed with SporeTracker. PLoS ONE 2013, 8, e58972. [CrossRef] [PubMed]

45. Paidhungat, M.; Setlow, P. Localization of a germinant receptor protein (GerBA) to the inner membrane of Bacillus subtilis spores. J. Bacteriol. 2001, 183, 3982-3990. [CrossRef] [PubMed]

46. Zheng, L.; Abhyankar, W.; Ouwerling, N.; Dekker, H.L.; van Veen, H.; van der Wel, N.N.; Roseboom, W.; de Koning, L.J.; Brul, S.; de Koster, C.G. Bacillus subtilis spore inner membrane proteome. J. Proteome Res. 2016, 15, 585-594. [CrossRef]

(C) 2020 by the authors. Licensee MDPI, Basel, Switzerland. This article is an open access article distributed under the terms and conditions of the Creative Commons Attribution (CC BY) license (http://creativecommons.org/licenses/by/4.0/). 